\title{
PENGARUH TAYANGAN HUMOR TERHADAP SHORT TERM MEMORY PADA MAHASISWA BARU
}

\author{
Ningrum Baha Lathifah, Amir Hasan Ramli, Faizah \\ ningrumbahalathifah@gmail.com \\ Program Studi Psikologi, Fakultas Ilmu Sosial dan Ilmu Politik, Universitas \\ Brawijaya
}

\begin{abstract}
ABSTRAK
Tujuan dari penelitian ini adalah untuk pengetahui pengaruh tayangan humor terhadap short term memory. Metode humor mampu mengurangi hormon kortisol dan hormon epinephrine sehingga informasi yang diterima dapat diantar ke otak untuk proses storage dan recall. Metode penelitian yaitu metode eksperimental dengan rancangan randomized matched two group design. Penelitian dilakukan kepada 50 partisipan mahasiswa Psikologi Universitas Brawijaya dan terdiri dari 2 kelompok yaitu kelompok kontrol dan kelompok eksperimen masing-masing 25 partisipan. Hasil uji independent sample t-test menyatakan bahwa terdapat pengaruh tayangan humor terhadap kemampuan Short Term Memory partisipan dengan nilai signifikansi 0,001 yang lebih kecil dari 0,05
\end{abstract}

Kata kunci: Tayangan humor, Short Term Memory, Mahasiswa Baru

Mahasiswa baru mengalami perbedaan pola dan sistem pembelajaran dari masa Sekolah Menengah Atas (SMA). Perubahan pola ini menuntut mahasiswa baru untuk dapat mengelola informasi yang mereka terima agar informasi tersebut dapat digunakan pada saat dibutuhkan. McCraty (Vitasari, 2010) menyatakan bahwa perasaan cemas yang dimiliki oleh mahasiswa baru dapat mengganggu prestasi mahasiswa tersebut. Kecemasan yang dialami mahasiswa baru dapat menghalangi kemampuan memori dan recall. Pacarora (Vitasari, 2010) menyatakan bahwa mahasiswa yang memiliki tingkat kecemasan tinggi dapat menghalangi pola pikir untuk berkembang, membentuk skema yang buruk dalam pikirannya, dan sangat berpotensial untuk mendapatkan hasil yang buruk saat ujian.

Terdapat berbagai cara agar memori yang mereka pelajari dapat melakukan recall atau pemanggilan informasi dan diharapkan tidak mengalami forgetting atau lupa. Beberapa cara dalam mempertahankan memori yaitu melakukan pengulangan (rehearsall), elaborative rehersall, deep processing, dan mnemonic (Wade dan Tavris, 2007).

Beberapa penelitian menunjukan bahwa metode humor merupakan salah satu cara dalam mempertahankan memori. Menggunaan metode humor dalam proses belajar mengajar mampu meningkatkan memori pada mahasiswa (Atir, 2010). Ziv (Wanzer, 2006), humor membuat mahasiswa memberi 
perhatian kepada pengajar terhadap materi yang disampaikan yang berhubungan langsung dengan memori. Cialdini (Wanzer, 2006) menyatakan bahwa humor membuat mahasiswa mengikuti kegiatan belajar dengan lebih terbuka, meningkatkan kemampuan belajar siswa, dan mampu belajar lebih giat terhadap permasalahan terkait materi yang diberikan.

Secara neurologis, humor dapat mengaktifkan bagian otak yaitu ventral tegmentum, ventral striatum, dan beberapa area yang berhubungan dengan emosi dan pemrosesan reward (Matthews, 2011). Area ventral tagmentum berfungsi membuat senyawa kimia dopamin yang disebar ke bagian otak lainnya yang membuat individu merasa nyaman dengan lingkungan sekitar. Ancaman dan stress merupakan hal yang menghambat seseorang untuk melakukan proses informasi dengan baik oleh otak. Menurut Jensen (Matthews, 2011), bermain dan tertawa dalam kegiatan humor diakui dapat digunakan untuk meningkatkan memori. Mengurangi stress melalui kegiatan humor adalah cara yang lebih baik dalam pemanggilan informasi. Dopamin kemudian mengaktifkan bagian hipokampus sehingga informasi yang disimpan dalam memori mampu bertahan dan dapat melakukan recall informasi tersebut (Chowdhury, 2012).

Gold (Wade dan Tavris, 2007) menyatakan bahwa emosi memiliki andil yang banyak dalam proses penyerapan informasi dan penyimpanan informasi. Penggunaan humor dalam suatu proses belajar akan menjadikan mood mahasiswa menjadi lebih baik. Jika mahasiswa memunculkan emosi yang positif, maka akan muncul arousal. Arousal memberikan stimulus kepada otak berupa petunjuk bahwa terdapat informasi yang penting, kemudian disandikan dan kemudian dapat dipanggil kembali jika dibutuhkan. Arousal didalamnya terdapat glukosa dan disebarkan ke seluruh otak sehingga meningkatkan memori secara langsung ataupun tidak langsung dengan cara mempengaruhi efek neutransmitter. Menurut Karol dan Gold (Wade dan Tavris 2007), penggunaan glukosa dalam dosis yang tepat membantu mahasiswa menyerap informasi dan kemudian menyimpan informasi tersebut.

Mahasiswa yang memiliki emosi negatif cenderung menimbulkan hormon kortisol yang biasanya muncul pada orang yang mengalami stress dan depresi sehingga sulit untuk mengaktifkan bagian hipokampus (Matthews, 2011)

Humor dalam penelitian ini dikemas dalam bentuk tayangan singkat. Tayangan humor mampu diserap lebih cepat diserap karena menggunakan dua panca indra, yaitu mata yang menangkap visualisasi tayangan humor dan telinga akan menangkap auditori dari tayangan humor.

Urgensi penelitian yaitu membantu mahasiswa baru atau mahasiswa yang memiliki kecemasan agar menggunakan metode belajar yang menyenangkan untuk memiliki kemampuan memori yang lebih baik. Peneliti tertarik melakukan penelitian ini karena jarangnya penelitian humor terhadap kognitif salah satunya yaitu memori. Dalam penelitian eksperimental, hipotesis menyatakan hubungan sebab akibat yaitu pengaruh variabel bebas terhadap variabel terikat. Hipotesis dari penelitian ini yaitu ada pengaruh yang signifikan dari tayangan humor terhadap short term memory pada mahasiswa baru. 


\section{METODE}

\section{Desain Penelitian}

Jenis desain eksperimental dalam penelitian ini menggunakan desain dua kelompok (two group design) berupa penelitian Randomized Two - Group Design, Posttest Only. Desain ini melakukan pengukuran sesudah (posttest) pemberian treatment pada kelompok eksperimen dan dan kontrol. (Seniati, Yulianto, dan Setiadi, 2011). Kelompok kontrol diberikan IST subtes ME, sedangkan kelompok eksperimen diberikan tayangan humor yang berjudul Malam Minggu Miko kemudian diberikan IST subtes ME. Hasil perhitungan IST subtes ME antara kelompok kontrol dan kelompok eksperimen akan dibahas dalam subbab lebih lanjut.

\section{Subjek Penelitian}

Peneliti mengambil populasi mahasiswa baru Psikologi Universitas Brawijaya Malang dikarenakan mahasiswa baru menghadapi situasi baru yang berbeda dengan situasi pada saat SMA (Sekolah Menengah Atas). Partisipan dari penelitian ini yaitu kelas B mata kuliah Psikologi Umum. Tahap selanjutnya yaitu random assignment pada partisipan kelas untuk menentukan kelompok eksperimen dan kelompok control menggunakan alat bantu perangkat lunak berupa randomizer. Kelompok eksperimen akan diberikan perlakuan berupa tayangan humor dan kelompok kontrol tidak diberikan perlakuan apapun. Jumlah total partisipan yaitu 50 mahasiswa. Perhitungan $\mathrm{G}^{*}$ Power menunjukkan bahwa untuk memperoleh effect size medium ( $\mathrm{f}=1,01)$ dengan power $=0,95$, jumlah minimum keseluruhan sampel yang diperlukan adalah 22 partisipan. Jadi, jumlah total partisipan dalam penelitian eksperimen ini sudah mencukupi.

\section{Instrumen Penelitian}

1. Intelligenz Strukture Test (IST) subtes Merk Aufgaben (ME). Subtes Merk Aufgaben digunakan untuk mengukur memori.

2. Tayangan Humor

Tayangan Humor yang digunakan yaitu Malam Minggu Miko

3. Informed Consent

Berfungsi sebagai persetujuan partisipan dalam penelitian dan mengikuti instruksi yang akan diberikan dalam proses eksperimen

4. Manipulation Check

Untuk melihat apakah video humor, cerita humor, dan gambar-gambar lucu dapat bekerja sesuai harapan.

\section{Analisis Data}

Analisis data menggunakan SPSS 20 dengan teknik Independent Sample T-Test

\section{HASIL}

Tabel 1.

Gambaran Partisipan

\begin{tabular}{ccccccc}
\hline $\begin{array}{c}\text { Kate- } \\
\text { gori }\end{array}$ & $\begin{array}{c}\text { Kelompok } \\
\text { Kontrol }\end{array}$ & $\begin{array}{c}\text { Kelompok } \\
\text { Eksperimen }\end{array}$ & TO- & Tum \\
lah & $\%$ & $\begin{array}{c}\text { Jum } \\
\text { TAh }\end{array}$ & \% & & \\
\hline Baik & 7 & 28 & 16 & 64 & 23 & 46 \\
Sekali & & & & & \\
Baik & 15 & 60 & 9 & 36 & 24 & 48 \\
Cukup & 3 & 12 & & 0 & 3 & 6 \\
Kurang & & 0 & & & 0 & 0 \\
Kurang & & & & & & \\
Sekali & & 10 & & 10 & & 10 \\
Jumlah & 25 & 0 & 25 & 0 & 50 & 0 \\
\hline
\end{tabular}

Kelompok kontrol memillki 28\% partisipan yang memiliki kemampuan memori baik sekali, $60 \%$ yang memiliki kemampuan memori baik, dan $25 \%$ yang memiliki kemampuan memori cukup. 
Kelompok eksperimen memiliki 64\% yang memiliki kemampuan memori baik sekali dan $36 \%$ yang memiliki kemampuan memori baik.

\section{Manipulation Check}

Manipulation Check diberikan kepada partisipan kelompok eksperimen yang diberikan tayangan humor yang berisi pertanyaan tingkat kelucuan tayangan humor yang telah diberikan. Angket ini bertujuan untuk mengukur apakah tayangan humor bertujuan untuk mengukur bahwa tayangan humor bekerja sesuai harapan. Manipulation Check ini memberikan penilaian rentang skala 1-9. Hasil dari rata-rata manipulation check adalah sebesar 6,72.

Hasil tersebut menunjukkan bahwa tayangan humor diatas nilai tengah yaitu 5 , sehingga tayangan humor tersebut menunjukan kelucuan.

\section{Uji Hipotesis}

Tabel 2

Hasil Uji Penelitian

\begin{tabular}{cccc}
\hline Kelompok & Sig & Mean & SD \\
\hline Eksperimen & \multirow{2}{*}{0,001} & 17,94 & 1,9 \\
Kontrol & & 15,84 & 3,4 \\
\hline
\end{tabular}

Hasil penelitian mnunjukan bahwa signifikansi (2-tailed) adalah 0,001. Karena 0,001 lebih kecil daripada 0,05 ( $p$ $<0,05)$ maka dapat disimpulkan bahwa hipotesis yaitu ada pengaruh yang signifikan dari tayangan humor terhadap short term memory mahasiswa baru. Kelompok eksperimen memiliki rata-rata yang lebih besar $(M=17,84$ dan $S D=1,9)$ dibandingkan rata-rata kelompok kontrol $(M=15,84$ dan $S D=3,4)$.

\section{DISKUSI}

Pembahasan Manipulation Check

Berdasarkan data yang diperoleh, dapat diketahui bahwa antara kelompok eksperimen memiliki mean 6,72 dari rentang skala 1 sampai 9 dengan arti tayangan humor diatas nilai tengah yaitu 5 dan termasuk kategori lucu.

\section{Pembahasan Hipotesis}

Proses memori memiliki tiga tahapan yaitu encoding, storage, dan retrieval (Wade dan Tavris, 2007). Tahapan encoding dilakukan dengan cara menghapalkan informasi berupa kata-kata dan kategori dari subtes ME (Merk Aufgaben). Tahapan encoding dilakukan secara sengaja karea ada tujuan untuk melakukan proses memori (Riyanti, Prabowo, dan Puspitawati, 2007). Tahapan storage yaitu tahapan mempertahankan proses penyimpanan karena informasi tersebut dibutuhkan untuk tes ME. Tahapan selanjutnya yaitu retrieval atau recall yaitu pemanggilan informasi kembali untuk digunakan yaitu pengerjaan soal-soal subtes ME.

Tes memori yang diberikan yaitu tes memori jangka pendek. Informasi yang dibutuhkan bersifat sementara dan terbatas, sehingga membutuhkan usaha menahan informasi untuk bertahan lebih lama. Jika tidak maka akan muncul lupa (forgeting). Lupa akhirnya membuat partisipan tidak menjawab soal atau menjawab opsi yang salah. Hal ini disebabkan karena adanya replacement dan interferensi. Replacement terjadi karena terdapat informasi baru yang muncul sehingga menhilangkan informasi 
yang lama. Selain itu juga terdapat faktor interferensi yaitu kesulitan membedakan informasi tersebut dengan informasi lainnya karena kemiripan informasi pada proses encoding maupun proses recall (Wade dan Tavris, 2007).

Hasil uji penelitian menunjukan bahwa terdapat pengaruh tayangan humor terhadap kemampuan memori (Sig 0,001 < 0,05). Hal ini dapat dilihat dari kemampuan short term memory pada kelompok yang diberikan tayangan humor (kelompok eksperimen) memiliki nilai lebih besar dibandingkan dengan kelompok yang tidak diberi tayangan humor (kelompok kontrol).

Penelitian eksperimental biologi yang dilakukan oleh G.S Bains (2014) menyatakan bahwa menonton tayangan humor memiliki pengaruh terhadap memori. Humor yang diasosiasikan dengan tertawa dapat mengurangi stress dan hormon kortisol serta merubah emosi dan mood seseorang. Selain itu menurut Wade dan Tavris (2007) tertawa akan melepaskan epinephrine dan memperbanyak endorfin.

Hormon kortisol dan hormon epinephrine merupakan hormon stres yang dapat mengganggu kinerja neuron-neuron pada hippocampus. Gangguan-gangguan tersebut akan menghambat proses memori pada otak. Partisipan pada kelompok eksperimen yang memberikan reaksi berupa tersenyum, tertawa, dan perasaan bahagia ketika menonton tayangan humor akan memunculkan hormon endorfin dan dopamin di otak sehingga menimbulkan perasaan nikmat (Rokade, 2011). Endorfin akan meningkatkan glukosa dalam darah. Glukosa akan memasuki otak dan mempengaruhi neutransmitter yang akan memperpanjang daya ingat (Wade dan Tavris, 2007). Hal ini disebabkan karena otak akan menghabiskan cadangan glukosa dengan cepat untuk menyelesaikan tugastugas sulit, terutama hippocampus yang merupakan gerbang masuk memori.

Hasil penelitian milik Hasanat \& Subandi (Zuchrufia, 2013) menyatakan bahwa humor mampu memunculkan emosi positif. Emosi positif dapat muncul karena tersnyum atau tertawa yang menimbulkan ekspresi wajah yang positif. Emosi positif yang ditimbulkan oleh aurosal akan memberikan stimulus dan petunjuk pada otak bahwa ada peristiwa atau informasi yang penting. Peristiwa atau informasi itu kemudian segera dilakukan penyandian (encoding) dan melakukan proses penyimpanan untuk digunakan kembali apabila dibutuhkan.

Partisipan kelompok kontrol memiliki kemampuan short term memory yang lebih kecil. Hal ini sesuai dengan penelitian yang dilakukan oleh Bains (2014) bahwa kelompok control memunculkan perasaan takut, cemas, dan stress akan tes sehingga membuat hormon kortisol meningkat. Hormon kortisol yang meningkat akan mengganggu kinerja hippocampus termasuk proses memori. Hal ini yang menjadi penyebab kemampuan short term memory kelompok kontrol lebih kecil.

Keterbatasan penelitian ini yaitu tidak adanya pembedaan jenis kelamin dalam pelaksanaan penelitian karena kemampuan short term memory dipengaruhi oleh jenis kelamin, efek kegembiraan timbul bukan karena adegan tayangan humor yang lucu melainkan karena kegembiraan tersebut menular dari partisipan lainnya dan penelitian ini tidak mengukur kecemasan dan emosi agar hasil lebih akurat. 


\section{KESIMPULAN}

Kesimpulan dari penelitian ini yaitu ada pengaruh yang signifikan dari tayangan humor terhadap kemampuan short term memory mahasiswa Program Studi Psikologi Universitas Brawijaya dan kelompok eksperimen yang diberikan tayangan humor memiliki kemampuan short term memory yang lebih besar dibandingkan kemampuan short term memory pada kelompok kontrol yang tidak diberikan tayangan humor.

Saran dari penelitian ini yaitu melakukan pengukuran emosi para partisipan penelitian agar dapat memastikan bahwa keterbangkitan emosi positif memang telah terjadi pada setiap partisipan penelitian, lebih baik penelitian dilakukan secara one by one agar rasa lucu yang ditimbulkan tidak disebabkan dari efek menular dan memperhatikan faktor jenis kelamin agar tidak menjadi variabel pengganggu.

\section{DAFTAR PUSTAKA}

Atir, Stav. Running Head: Memory For Information Paired With Humor 1 Memory For Information Paired With Humorous, Relevant Jokes. (Thesis pada Yale University, 2010). Hal 3

Bains, Gurinder Singh., Berk, Lee S., Daher, Noha., Lohman, Everett., Schwab, Ernie., Petrofsky, Jerrold., Deshpande, Pooja. (2014). The Effect Of Humor On Short-Term Memory In Older Adults: A New Component For Whole-Person Wellness.http://www.ncbi.nlm.nih.go v/pubmed/24682001 Chowdhury $\underline{\mathrm{R}}$, Guitart-Masip M, Bunzeck $\underline{\mathrm{N}}$, Dolan RJ, Düzel E). Dopamine Modulates Episodic Memory Persistence In Old Age. Jurnal pada Nat Rev Neuroscience. 2012). DOI:
10.1523/JNEUROSCI.1278-

12.2012 .

Matthews, Melissa Lee Mccartney. A Funny Thing Happened On The Way To The Hippocampus: The Effects Of Humor On Student Achievement And Memory Retention. (Disertasi pada Arizona State University. 2011)

Riyanti B.P Dwi, Hendro Prabowo, Ira Puspitawati. (2009). Psikologi Umum 1.(Online). Diakses dari http://elearning.gunadarma.ac.id/doc modul/psikologi_umum_1/

Rokade.International Conference on Chemical, Biological and Environmental Sciences: Release Of Endomorphin Hormone And Its Effects On Our Body And Moods, Jurnal tidak diterbitkan: R.B. Attal Arts, Science, \& Commorce College. Page No. 436-438. (Academic Year : 2011-2012).

Seniati, Liche., Yulianto, Aries., Dan Setiadi, Bernadette N. (2011). Psikologi Eksperimen. Jakarta: PT Indeks Kelompok Gramedia.

Vitasari, Prima., Wahab, Muhammad Nubli Abdul., Othman, Ahmad., Awang, Muhammad Ghani. (2010). A Research for Identifying Study Anxiety Sources among University Students. International Education Studies Vol. 3, No. 2; May 2010.Universiti Malaysia Pahang.

Wade, Carole., Tavris, Carol. (2007). Psikologi Edisi Kesembilan Jilid 2. Jakarta: Erlangga.

Walter, Marc., Ha“Nni, Beat., Haug, Myriam., Amrhein, Isabelle., Roubicek, Eva Krebs., Spahn, Franz Mu"Ller., And Savaskan, Egemen. (2014). Humour Therapy In Patients With Late-Life Depression Or 
Pengaruh Tayangan Humor terhadap Short Term Memory pada Mahasiswa Baru

Alzheimer's Disease: A Pilot Study. International Journal of Geriatric Psychiarty. Wiley Interscience (www.interscience.wiley.com)

Wanzer, M.B., Frymier, A.B., Wojtaszczyk, A.M., \& Smith, T. (2006). Appropriate and inappropriate uses of humor by teachers. Communication Education, $55,178196$.

Zuchrufia, Afnia Rosa. (2013). Pengaruh Menonton Film Drama Komedi Korea Terhadap Emosi Positif pada Mahasiswa yang Sedang Menempuh Skripsi. Empathy Jurnal Fakultas Psikologi. Universitas Ahmad Dahlan. 